\title{
Glucose Homeostasis during the Perinatal Period in Normal Rats and Rats with a Glycogen Storage Disorder
}

\author{
Kevin R. Gain, Rex Malthus, and Colin Watts, Department of Clinical \\ Biochemistry, University of Otago Medical School, Dunedin, New Zealand
}

A B S T R A C T The fetal rat mobilizes liver glycogen during parturition for use as a glucose source until the onset of gluconeogenesis at $2 \mathrm{~h}$ after birth. A rat strain (NZR/Mh) unable to mobilize liver glycogen because of a phosphorylase $b$ kinase deficiency has been used to assess the importance of liver glycogen in glucose homeostasis of the newborn.

In normal rats the mean blood glucose concentration of the fetus measured at various times up to $24 \mathrm{~h}$ after natural birth ranged between 3.7 and $5.4 \mathrm{mM}$. In contrast, fetuses of the affected rats were hypoglycemic before birth $(2.02 \pm 0.15 \mathrm{mM})$, and by $1 \mathrm{~h}$ after birth the blood glucose had decreased to $0.74 \pm 0.14 \mathrm{mM}$. Concentrations increased by $4 \mathrm{~h}$ to $1.48 \pm 0.17 \mathrm{mM}$ and by $24 \mathrm{~h}$ reached values not significantly different from the normal newborn rats. Changes in plasma insulin over the perinatal period were similar in both groups although concentrations were always significantly lower in the affected rats.

The findings demonstrate the crucial role of the fetal liver glycogen store in the maintenance of normoglycemia in the newborn. The normal rat does not develop hypoglycemia when born naturally and left with the mother after birth (in contrast to other studies in which the newborn were taken by cesarian delivery $1 \mathrm{~d}$ prematurely and kept in an artificial environment without food). The rats with the glycogen storage disorder experienced severe hypoglycemia without any apparent effects, which raises questions concerning alternative fuels available to and utilized by the newborn.

\section{INTRODUCTION}

The normal fetal rat accumulates glycogen in the liver over the last $5 \mathrm{~d}$ of gestation (1-3). This store of glycogen is used for the maintenance of the blood glucose concentration over the period between parturition and the onset of suckling $\sim 2 \mathrm{~h}$ after birth (4). A strain of rats (NZR/Mh) with a glycogen storage disorder has been

Received for publication 23 May 1980 and in revised form 27 October 1980. bred in this department. These animals have enlarged livers containing over twice as much glycogen as in normal fed rats, which is not appreciably reduced by starvation or mobilized by intravenous glucagon. Glycogen concentrations in most other tissues are comparable with those of normal rats except for small differences in lung and kidney. The condition is caused by a deficiency of phosphorylase kinase activity and has been shown to be an autosomal recessive trait (5).

Despite their inability to mobilize liver glycogen the rats are able to maintain their blood glucose at a concentration that is only slightly lower than that found in normal animals in the fed state, and that does not fall significantly even after $72 \mathrm{~h}$ starvation (5). In all other respects they appear healthy with a normal life span and no evidence of increased fetal or neonatal mortality. It was of particular interest therefore, to study these animals over the perinatal period to determine to what extent hypoglycemia occurs and whether mobilization of liver glycogen is completely or only partially prevented by the genetic defect. The present report describes a comparison of the blood glucose, plasma insulin, and liver glycogen during the 24-h periods before and after birth of normal and affected rats.

\section{METHODS}

Pregnant rats. Observations were made on rats of the NZR/Mh strain homozygous for the liver phosphorylase $b$ kinase deficiency (gsd/gsd) and normal rats of a random bred Wistar strain. All animals were housed in a conventional animal room at $19-25^{\circ} \mathrm{C}$ and fed a standard rat diet (5). Gestational age was calculated from the finding of sperm in a vaginal smear, the day on which a positive smear was found being taken as day zero. Approximately 20 litters each of gsd/gsd and normal animals were studied. Birth was allowed to occur naturally with the time recorded for each pup as the expulsion of the intact feto-placental unit from the uterus. The pups were marked according to their time of birth. All animals used for the zero hour postnatal group were sampled before the placenta was detached by the mother and the feto-placental unit was kept intact during taking of blood and liver samples. For later ages the pups were left with the mother until the time of sampling. Samples were taken from the 
fetuses after pentobarbital anesthesia of the mother (10 $\mathrm{mg} / 100 \mathrm{~g}$ body wt i.p.).

Blood glucose and insulin measurements. Blood was obtained from fetal and newborn animals from the jugular vessels and collected in heparinized tubes. Wherever possible analyses were performed on samples from individual pups, otherwise blood from two animals was pooled. Maternal blood samples were obtained by cardiac puncture. The blood glucose concentration was determined immediately in whole blood, after deproteinization with uranyl acetate $(0.16$ $\mathrm{g} / 100 \mathrm{ml}$ ), using a glucose oxidase/peroxidase procedure (GOD-Perid method, C. F. Boehringer and Sons, Mannheim, West Germany). Plasma insulin was measured by radioimmunoassay against a rat insulin standard (Novo Research Institute, Copenhagen, Denmark, lot R171) as has been described previously (6).

Liver glycogen measurements. Whole livers were taken from both fetal and newborn animals for glycogen determinations. The tissue was placed in $1 \mathrm{ml} \mathrm{KOH}(30 \mathrm{~g} / 100 \mathrm{ml})$ if processed immediately or frozen in liquid $\mathrm{N}_{2}$ and stored at $-20^{\circ} \mathrm{C}$ for later analysis. Glycogen was measured after digestion of the tissue and precipitation of the glycogen with ice-cold ethanol (7). The glycogen was then digested by $\alpha$ amyloglucosidase and measured as glucose equivalents (5).

Statistical analysis. Values for groups of animals are presented as the mean \pm SEM. Statistical significance was determined using the $t$ test for unpaired data.

\section{RESULTS}

We have shown previously that the blood glucose concentrations of naturally delivered normal newborn rats remain constant at around $4 \mathrm{mM}(4)$ in contrast to the marked hypoglycemia reported by others using rats delivered by cesarian section $(8-11)$. These findings have been extended and confirmed in the present study as shown in Fig. 1. Fetal blood glucose concentrations rose significantly from day 21 to day 22 of gestation $(P<0.005)$ and were maintained at a similar level during birth and for the first hour afterwards. There was a significant fall $(P<0.025)$ to the second hour after birth and thereafter the levels remained remarkably constant over the time studied. In marked contrast, the blood glucose of the gsd/gsd rats was very low before birth and fell even further during the first hour

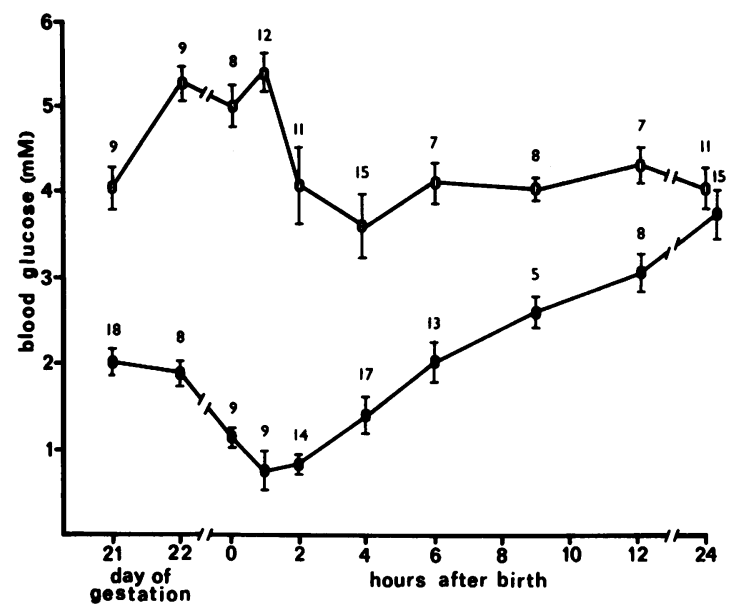

Figure 1 Blood glucose concentrations before and after birth of normal and gsd/gsd rats. Blood was taken from fetal rats at days 21 and 22 of gestation and newborn rats at selected times after extrusion of the feto-placental units. $\bigcirc$, normal rats , gsd/gsd rats. Results are plotted as means \pm SEM with the number of observations shown.

after birth to reach a minimum of $0.74 \pm 0.14 \mathrm{mM}$. Furthermore the rise in the fetal blood glucose concentrations seen in normal rats from days 21 to 22 was absent in the gsd/gsd animals. From $2 \mathrm{~h}$ after birth there was a steady increase in blood glucose and by $24 \mathrm{~h}$ the levels were not significantly different in the two strains $(3.72 \pm 0.30$ and $4.03 \pm 0.29 \mathrm{mM}$ for $g s d / g s d$ and normal rats, respectively).

Table I shows the changes in maternal and fetal blood glucose concentrations over the last $2 \mathrm{~d}$ of gestation. The rise seen in the fetal blood glucose of normal rats before birth coincided with a rise in the maternal levels over the same period. In contrast, there was no rise in maternal or fetal levels in the gsd/gsd rats before birth.

The changes in blood glucose concentrations in both the normal and gsd/gsd rats are consistent with the observed changes in liver glycogen content (Fig. 2).

TABLE I

Changes in Maternal and Fetal Blood Glucose Concentrations over the Last 24 h of Gestation

\begin{tabular}{|c|c|c|c|c|}
\hline \multirow{3}{*}{$\begin{array}{l}\text { Gestational } \\
\text { age }\end{array}$} & \multicolumn{4}{|c|}{ Blood glucose } \\
\hline & \multicolumn{2}{|c|}{ Normal } & \multicolumn{2}{|c|}{ gsd/gsd rats } \\
\hline & Maternal & Fetal & Maternal & Fetal \\
\hline$d$ & \multicolumn{2}{|c|}{$m M$} & \multicolumn{2}{|c|}{$m M$} \\
\hline 21 & $5.11 \pm 0.24(9)$ & $4.07 \pm 0.24(9)$ & $3.97 \pm 0.13(7)^{*}$ & $2.02 \pm 0.15(18)$ \\
\hline 22 & $6.33 \pm 0.68(9)$ & $5.33 \pm 0.19(9)$ & $3.47 \pm 0.26(6) \S$ & $1.89 \pm 0.16(8) \ddagger$ \\
\hline
\end{tabular}

Results expressed as mean \pm SEM with number of observations in parentheses.

$* P<0.005$ compared with equivalent normal group.

$\$ P<0.001$ compared with equivalent normal group.

$\S P<0.01$ compared with equivalent normal group. 


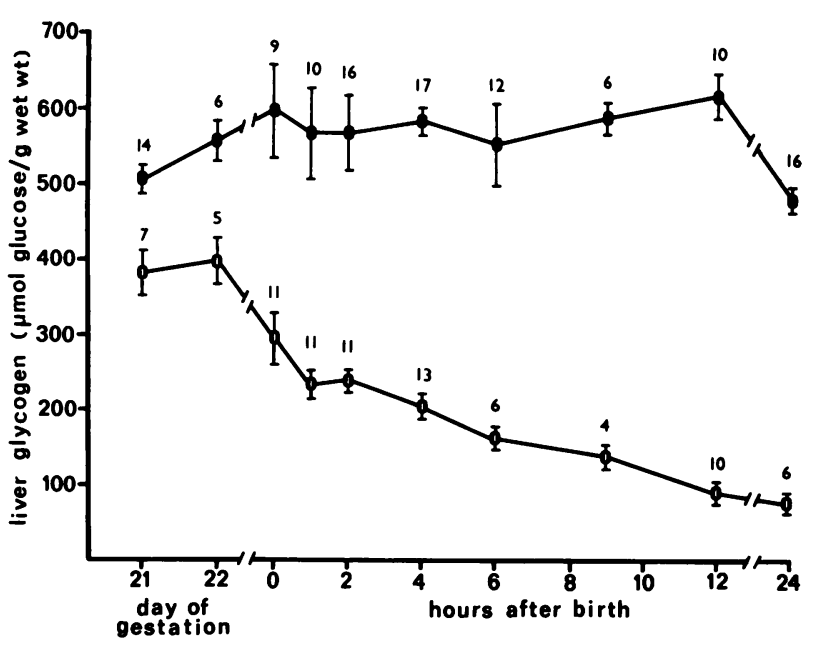

Figure 2 Liver glycogen content before and after birth of normal and gsd/gsd rats. Liver samples were taken at the same times as shown in Fig. 1, $\bigcirc$, normal rats;, gsd/gsd rats. Results are plotted as means \pm SEM with the number of observations shown.

In normal pups liver glycogen fell during and immediately after parturition. This fall corresponded with the maintained blood glucose concentration up to $1 \mathrm{~h}$ after birth. In contrast, in gsd/gsd pups there was no significant change in the liver glycogen content after birth although there appeared to be a small increase in liver glycogen over the last $24 \mathrm{~h}$ of gestation $(508 \pm 13$ to $560 \pm 27 \mu \mathrm{mol}$ glucose/g liver).

The changes in plasma insulin concentration over the same period are shown in Fig. 3. Before birth very high concentrations were seen in plasma from normal animals. The levels fell rapidly from $1,199 \pm 161 \mathrm{pM}$ at $21 \mathrm{~d}$ of gestation to $297 \pm 50 \mathrm{pM}$ at $1 \mathrm{~h}$ after birth. From $2 \mathrm{~h}$ there was a further slow fall to $193 \pm 55 \mathrm{pM}$ at $12 \mathrm{~h}$. In gsd/gsd rats a similar pattern was seen, there being a steady fall in insulin concentrations from $479 \pm 44 \mathrm{pM}$ at $21 \mathrm{~d}$ gestation to $91 \pm 11 \mathrm{pM}$ by $4 \mathrm{~h}$ after birth. At all times the plasma insulin concentrations in the gsd/gsd pups were significantly lower than in the normal pups $(P<0.05)$.

Table II shows the insulin/glucose ratios in the fetal and newborn rats. Although there were large differences in both glucose and plasma insulin between the gsd/gsd and normal fetuses at day 21 of gestation, the ratios were remarkably similar. At day 22 , however, there was a dissociation between the glucose and insulin with a profound fall in plasma insulin associated with a rise in blood glucose in the normals, and a less pronounced fall in insulin with a stable blood glucose in the gsd/gsd fetuses, giving different ratios in the two groups. Over the period from 4 to $12 \mathrm{~h}$ after birth, the ratio had stabilized in the normals to values approaching those seen in fed adult rats, while the gsd/gsd newborn ratio had decreased to similar levels by $12 \mathrm{~h}$.

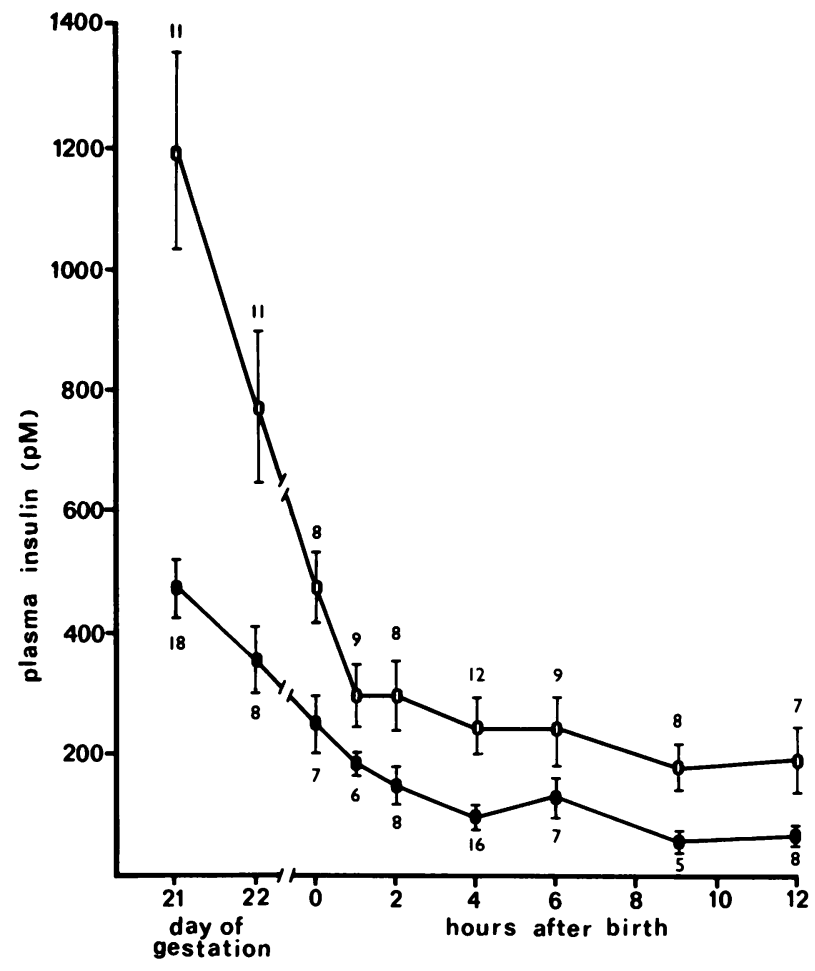

FIGURE 3 Plasma insulin before and after birth of normal and gsd/gsd rats. Blood samples were taken as shown in Fig. 1. $\bigcirc$, normal rats; 0 , gsd/gsd rats. Results are plotted as means \pm SEM with the number of observations shown.

\section{DISCUSSION}

Before birth, the blood glucose concentration of the normal fetus is only $20 \%$ below that of the mother at day 21 of gestation and the concentrations in both mother and fetus rise in proportion over the $24 \mathrm{~h}$ preceding birth (Table I). In comparison, the blood glucose of the gsd/gsd fetus is only $50 \%$ that of the mother and there is no rise in either before birth. The lower fetal glucose level in relation to the mother in these rats could be due to the inability of the gsd/gsd fetus to con-

TABLE II

Changes in the Plasma Insulin/Glucose Ratio over the Perinatal Period

\begin{tabular}{lcc}
\hline & Normal & gsd/gsd \\
\hline 21 d gestation & $288 \pm 38(9)$ & $270 \pm 28(19)$ \\
22 d gestation & $131 \pm 18(9)$ & $191 \pm 17(8)^{*}$ \\
4 h postnatal & $63 \pm 10(12)$ & $70 \pm 12(17)$ \\
12 h postnatal & $42 \pm 10(7)$ & $25 \pm 3(8)$ \\
\hline
\end{tabular}

All ratios were calculated from paired observations and are given as mean \pm SEM. The number of observations is given in parentheses.

${ }^{*} P<0.01$ compared with normal. 
tribute to the maintenance of its own blood glucose by utilizing its liver glycogen, i.e., absence of turnover of liver glycogen which has been proposed as a normal physiological process at this stage of gestation $(1,12)$.

The data presented here clearly indicate that in normal newborn rats, rapid breakdown of liver glycogen occurs during and immediately after natural birth. This effectively maintains their blood glucose concentrations for at least $1 \mathrm{~h}$ after birth preventing the development of hypoglycemia before the onset of suckling at $\sim 2 \mathrm{~h}$. The normal newborn rats in the zero hour group were taken at various times during birth of the litter and the group presumably consists of animals whose placentae had been detached from the uterus for various times, depending on their position in the uterine horns. However, their blood glucose concentrations did not fall. This, coupled with the difference in liver glycogen concentrations before (day 22) and after (zero hour) birth, indicates that mobilization of glycogen occurs simultaneously with or even before detachment of the placenta.

Other studies that demonstrated hypoglycemia in newborn rats (8-11) have involved premature delivery by cesarian section on day 21 of gestation and the pups being kept at $37^{\circ} \mathrm{C}$ without food. The blood glucose changes in normal newborn rats in the present work, as well as in our previous study (4), clearly show that hypoglycemia is not a consequence of natural birth. We consider that our studies more accurately describe the normal physiological responses of the newborn rat than those reported by others.

The most striking finding in the present study was the severe hypoglycemia experienced by the gsd/gsd pups in the first few hours after birth. This clearly illustrates the essential role of liver glycogen in the maintenance of normal blood glucose concentrations over the perinatal period, as in normal animals the changes in blood glucose match the changes in hepatic glycogen, while the failure of the gsd/gsd pups to maintain their blood glucose levels would appear to stem from their inability to mobilize liver glycogen. The slow rise in the blood glucose concentrations from $2 \mathrm{~h}$ onwards in these pups is presumably related to suckling, and to the onset of gluconeogenesis, which has been shown to increase linearly in normal rats from 2 to 6 $h$ after birth (13). However, the blood glucose of the normal rats did not increase during the same period and therefore it appears likely that the balance of fuel utilization is changed in the hypoglycemic gsd/gsd pups to produce a sparing effect on the blood glucose.

Despite the severe hypoglycemia following birth, the gsd/gsd rats showed no signs of distress. Mortality was not increased over the perinatal period compared to the normal rats, and the gsd/gsd pups appeared just as active as the normals after birth. The only apparent difference between the two groups was the lower birth weight of the gsd/gsd pups $(4.76 \pm 0.15 \mathrm{~g})$ compared with the normal pups $(5.47 \pm 0.07 \mathrm{~g})$. We consider that this is probably a strain difference as adult NZR/Mh rats are notably smaller than those of the random-bred colony. Within the strain, the offspring of mixed homozygous/heterozygous litters grow at similar rates and cannot at any stage of growth be distinguished by weight alone. It is unlikely that the weight difference was due to a limited supply of glucose to the gsd/gsd fetuses before birth as mixed litters obtained from homozygous mothers with some degree of hypoglycemia had the same mean fetal weight as those of mixed litters from heterozygous mothers with relatively normal blood glucose (unpublished observations).

These observations indicate that the newborn gsd/ gsd rat is able to survive the hypoglycemia without undue consequences. This requires that either alternative fuels are available and/or the rat has somehow adapted to hypoglycemia in utero. The fetal rat has very little store of lipid (14) and is unable to carry out appreciable gluconeogenesis both before and immediately after birth $(13,15,16)$. The adult gsd/gsd rats may also utilize alternative energy sources during starvation and pregnancy. The utilization of individual fuels by adult and fetus may be modified by the availability of other fuels (17). Ketone bodies (18), free fatty acids (19), lactate (20), and amino acids (21) could be involved. Obviously, a comprehensive study will be necessary to elucidate this complex subject.

It is difficult to explain the high plasma insulin concentrations observed in the normal fetal rat. Hyperinsulinemia in late gestation in the rat has been reported previously $(6,22,23)$ and it has been proposed recently that fetal hyperinsulinemia results from stimulation of the $\beta$-cell by a factor released from the placenta (24). The present results could support this concept. However, we have evidence to show that the insulin species measured by radioimmunoassay in late gestation is not native insulin, but primarily a higher molecular weight species that vanishes at birth to leave only native insulin in the newborn plasma (25). This would fit with the normalization of the insulin/glucose relationship that occurs soon after birth in both the normal and gsd/gsd rats.

The present study using a strain of rats that lack the ability to mobilize liver glycogen has clearly demonstrated the central and important role of the hepatic glycogen store in the fetus for the maintenance of normoglycemia following natural birth. The data presented also strongly support the contention that glycogen mobilization is initiated during the process of birth so that with a sudden cessation of maternal nutrient supply and exposure to the colder extrauterine environment, the newborn rat has a good supply of glucose immediately available. The finding that the gsd/gsd rats are able to tolerate hypoglycemia in utero and 
severe hypoglycemia after birth without any adverse effects raises important questions concerning the fuels available to, and utilized by the normal fetal and newborn rats, and also what adaptive processes may be induced by a major defect in carbohydrate metabolism.

\section{ACKNOWLEDGMENTS}

We thank Miss Julie Ockwell and Miss Annette Coubrough for their technical assistance.

This work is supported by a grant from the Medical Research Council of New Zealand.

\section{REFERENCES}

1. Watts, C., and K. R. Gain. 1976. Glycogen metabolism in the developing rat. Biochem. J. 160: 263-270.

2. Devos, P., and H-G. Hers. 1974. Glycogen metabolism in the liver of the foetal rat. Biochem. J. 140: 331-340.

3. Schwartz, A. L., and T. W. Rall. 1973. Hormonal regulation of glycogen metabolism in neonatal rat liver. Biochem. J. 134: 985-993.

4. Gain, K. R., and C. Watts. 1976. Glucose homeostasis in the developing rat II. Blood glucose, plasma insulin and hepatic glycogen in the newborn rat. Biol. Neonate. 30 : 35-39.

5. Malthus, R., D. G. Clark, C. Watts, and J. G. T. Sneyd. 1980. Glycogen storage disease in rats, a genetically determined deficiency of liver phosphorylase kinase. Biochem. J. 188: 99-106.

6. Watts, C., K. R. Gain, and P. L. Sandin. 1976. Glucose homeostasis in the developing rat I. Blood glucose and immunoreactive insulin in the later stages of gestation of the foetal rat. Biol. Neonate. 30: 88-94.

7. Lo, S., J. C. Russell, and A. W. Taylor. 1970. Determination of glycogen in small tissue samples. J. Appl. Physiol. 28: 234-236.

8. Cake, M. H., and I. T. Oliver. 1969. The activation of phosphorylase in neonatal liver. Eur. J. Biochem. 11: $576-581$.

9. Snell, K., and D. G. Walker. 1973. Glucose metabolism in the newborn rat. Temporal studies in vivo. Biochem. J. 132: 739-752.

10. Snell, K., and D. G. Walker. 1978. Glucose metabolism in the newborn rat: the role of insulin. Diabetologia. 14: $59-64$.
11. Girard, J. R., G. S. Cuendet, E. B. Marliss, A. Kervran, M. Rieutort, and R. Assan. 1973. Fuels, hormones, and liver metabolism at term and during the early postnatal period in the rat. J. Clin. Invest. 52: 3190-3200.

12. Gilbert, M., and J. Bourbon. 1978. Turnover of liver glycogen in the rat foetus. Biochem. J. 176: 785-789.

13. Pearce, P. H., B. J. Buirchell, P. K. Weaver, and I. T. Oliver. 1974. The development of phosphopyruvate carboxylase and gluconeogenesis in neonatal rats. Biol. Neonate. 24: 320-329.

14. Widdowson, E. M. 1950. Chemical composition of newly born mammals. Nature (Lond.). 166: 626-628.

15. Philippidis, H., and F. J. Ballard. 1969. The development of gluconeogenesis in rat liver. Experiments in vivo. Biochem. J. 113: 651-657.

16. Ballard, F. J. 1971. The development of gluconeogenesis in rat liver. Controlling factors in the newborn. Biochem J. 124: 265-274.

17. Freinkel, N. 1978. The role of nutrition in medicine: recent developments in fuel metabolism.J. Am. Med. Assoc. (JAMA). 239: 1868-1872.

18. Shambaugh, G. E., III, S. C. Mrozak, and N. Freinkel. 1977. Fetal fuels I: utilization of ketones by isolated tissues at various stages of maturation and maternal nutrition during late gestation. Metab. Clin. Exp. 26: 623-635.

19. Herrera, E., and N. Freinkel. 1975. Metabolites in the liver, brain, and placenta of fed or fasted mothers and fetal rats. Horm. Metab. Res. 7: 247-249.

20. Freinkel, N. 1965. Effects of the conceptus on maternal metabolism during pregnancy. In On the Nature and Treatment of Diabetes. International Congress Series 84. B. S. Leibel and G. A. Wrenshall, editors. Excerpta Medica, Amsterdam. 679-691.

21. Freinkel, N., and B. E. Metzger. 1975. Some considerations of fuel economy in the fed state during late human pregnancy. In Early Diabetes in Early Life. R. A. Camerini-Davalos and H. S. Cole, editors. Academic Press, Inc., New York. 289-301.

22. Cohen, N. M., and R. C. Turner. 1972. Plasma insulin in the foetal rat. Biol. Neonate. 21: 107-111.

23. Felix, J. M., M. T. Sutter, B. Ch. J. Sutter, and R. Jacquot. 1972. Circulating insulin and tissular reactivity to insulin in the rat during the perinatal period. Horm. Metab. Res. 3: 71-75.

24. Sodoyez-Goffaux, F. R., J. C. Sodoyez, and C. J. De Vos. 1979. Insulin secretion and metabolism during the perinatal period in the rat. J. Clin. Invest. 53: 1095-1102.

25. Gain, K. R., and C. Watts. 1979. Immunoreactive insulin in the fetal rat. Proc. Univ. Otago Med. Sch. 57: 35-36. 